\title{
GENETIC DIVERSITY \\ OF TEA PLANTS (CAMELLIA SINENSIS (L.) KUNTZE) GROWING IN THE RUSSIAN HUMID SUBTROPICS
}

\author{
Gvasaliya M. V. \\ Federal State Budgetary Scientific Institution \\ "Russian Research Institute of Floriculture and Subtropical Crops", \\ c. Sochi, Russia, e-mail:m.v.gvasaliya@mail.ru
}

The paper presents a material on the genetic diversity of industrial tea plantations growing the subtropics of Russia. Cultivars-populations of Bakhtadze K. E. were widely spread in tea farms, and the main tea cultivars-populations were evaluated. It is noted that the Chinese variety occupies the main place among tea plantations in the Russian humid subtropics, and the cultivar-population 'Kimyn', thanks to its high yield and frost resistance, has a special preference among tea-growers and has already given rise to many well-known cultivars such as 'Matsestinsky' and 'Karatum'. Despite the merits of the tea cultivars-populations, they can not compete with varietal plantations, which differ in the homogeneity of biological and economic characteristics. The cultivars of Tuov M. T. breeding and perspective mutant forms of Georgian scientists are recommended in order to lay high-quality varietal tea plantations.

Key words: tea plant, industrial tea plantations, varieties of tea, breeding, cultivars, cultivars-populations, promising mutant forms of Georgian scientists.

УДК 634.22:574.1

doi: 10.31360/2225-3068-2018-66-34-40

\section{СОРТА СЛИВЫ ДОМАШНЕЙ ДЛЯ ОПТИМИЗАЦИИ ЮЖНОГО СОРТИМЕНТА}

Заремук Р. ШІ.

\author{
Федеральное государственное бюджетное научное учреждение \\ «Северо-Кавказский федеральный научный центр садоводства, виноградарства, виноделия», \\ г. Краснодар, Россия, е-mail: zaremuk_rimma@mail.ru
}

Представлены сорта сливы домашней отечественной селекции, созданные в нестабильных и стрессовых условиях среды, характеризующиеся высоким адаптивным и продуктивным потенциалом. Сорта местной селекции 'Прикубанская', 'Краснодарская', 'Милена', 'Подруга', 'Герцог', 'Красотка', 'Чародейка' отличаются от ряда интродуцированных и стандартных сортов по основным хозяйственно-ценным признакам: засухоустойчивость, зимостойкость, устойчивость к основным болезням, продуктивности (скороплодность, период вступления в плодоношение, урожайность) и качеству плодов (масса и размер плода, биохимический состав, дегустационная оценка). Дана полная характеристика новым сортам сливы отечественной селекции, переданным в Государственное испытание и включённым в Государственный реестр селекционных достижений, допущенных для широкого промышленного 
Глава 2. Интродукция и сортоизучение

использования в условиях Северного Кавказа. Представленные сорта сливы домашней рекомендуются для оптимизации современного сортимента и дальнейшей селекционной работы в качестве источников ценных признаков.

Ключевые слова: слива, сорт, селекция, адаптивность, продуктивность, качество плодов.

Современное садоводство направленно на интенсификацию элементов технологии возделывания плодовых культур и, прежде всего, сорта. С учётом негативных изменений погодных условий возрастает роль более устойчивых к разным типам стрессов сортов, особенно отечественной селекции. К настоящему времени создано много отечественных сортов сливы домашней. Однако большинство из них не всегда отвечают тем требованиям, которые выдвигаются к сортам, в силу низкой адаптивности, урожайности или технологичности и др. Совмещение в одном сорте комплекса признаков - основная проблема селекционеров, решение которой возможно за счёт привлечения в направленные скрещивания новых сортов как зарубежной, так и отечественной селекции. Большинство современных сортов сливы были получены с использованием в качестве родительских форм старых западноевропейских и отечественных сортов: 'Венгерка Альбаха', 'Ренклод Альтана', 'Венгерка ажанская', 'Венгерка итальянская', 'Анна Шпет’, 'Великий Герцог', 'Ренклод зелёный', 'Изюм кубанский', 'Стенлей', 'Кабардинская ранняя’ и другие. С использованием некоторых из этих сортов были получены сорта сливы домашней: 'Прикубанская', 'Краснодарская', 'Милена', 'Подруга', 'Герцог', 'Красотка', 'Чародейка', отличающиеся от интродуцированных и некоторых отечественных сортов по адаптивности к местным условиям выращивания, урожайности, качеству плодов и другим признакам. Вместе с тем, необходимо отметить, что и они не отвечают всем предъявляемым требованиям $[1,2,4,6,7]$.

В связи с этим, очевидна актуальность дальнейшего селекционного улучшения сортимента сливы для южного садоводства, определяющая цель исследований - создание нового поколения сортов сливы домашней на основе доноров и источников ценных признаков, а также с использованием современных молекулярно-генетических подходов.

Объекты и методы исследований. Объектами исследований являются сорта сливы домашней селекции, находящиеся в ЦКП «Генетические коллекции садовых культур» СКФНЦСВВ и в ОПХ «Центральное».

Исследования ведутся согласно «Программы и методики селекции плодовых, ягодных и орехоплодных культур» (Орел, 1999); «Программы Северокавказского центра по селекции плодовых, ягодных, цветочно-декоративных культур и винограда на период до 2030 г.» (Краснодар, 2013). 
Обсуждение результатов. Как отмечалось выше в последние годы созданы сорта сливы, комплексная оценка которых в стрессовых условиях последних лет дала возможность получить новые качественные и количественные характеристики, обуславливающие возможности их использования в различных технологиях производства плодовой продукции в условиях южного садоводства.

В процессе оценки устойчивости сортов к комплексу стрессов (зимостойкость, засухоустойчивость, устойчивость к болезням и др.) установлено, что они обладают разным уровнем адаптивности. Так сорта 'Милена' и 'Красотка' отнесены к высоко-адаптивным, а у остальных сортов адаптивность выше среднего. Урожайность изученных сортов при схеме посадки $6 \times 4$ м варьировала от 17,8-21,5 т/га. Более урожайными в последние годы были сорта 'Чародейка', 'Подруга', 'Краснодарская'. По качеству плодов выделены сорта 'Милена', 'Подруга', 'Герцог' и 'Чародейка', средняя масса плода которых была в пределах 44,4-52,5 г и дегустационная оценка - 4,7-4,8 баллов (табл. 1).

Таблийа 1

Характеристика новых сортов сливы домашней селекции СКФНЦСВВ, 2015-2017 гг., ОПХ «Центральное»

\begin{tabular}{|l|c|c|c|c|c|}
\hline \multicolumn{1}{|c|}{ Сорта } & Адаптивность & $\begin{array}{c}\text { Урожай- } \\
\text { ность, } \\
m / 2 a\end{array}$ & $\begin{array}{c}\text { Средняя } \\
\text { масса } \\
\text { плода, } \\
2\end{array}$ & $\begin{array}{c}\text { Вкус } \\
\text { плода, } \\
\text { балл }\end{array}$ & $\begin{array}{c}\text { Высота } \\
\text { дерева, } \\
\text { м }\end{array}$ \\
\hline 'Прикубанская' & выше средней & 18,0 & 31,2 & 4,5 & 3,6 \\
\hline 'Краснодарская' & выше средней & 20,5 & 41,3 & 4,7 & 3,7 \\
\hline 'Милена' & высокая & 18,0 & $\mathbf{4 6 , 3}$ & 4,8 & 3,8 \\
\hline 'Подруга' & выше средней & 20,2 & $\mathbf{4 4 , 4}$ & 4,8 & 3,6 \\
\hline 'Герцог' & выше средней & 17,8 & $\mathbf{4 8 , 6}$ & 4,7 & 3,5 \\
\hline 'Красотка' & высокая & 18,4 & 35,5 & 4,7 & 3,7 \\
\hline 'Чародейка' & выше средней & 21,5 & $\mathbf{5 2 , 5}$ & 4,7 & 3,6 \\
\hline
\end{tabular}

По силе роста все сорта сливы отнесены к среднерослыми, что позволяет использовать для современных формировок: комбинированная веретеновидная (свободное веретено, русское веретено); плоская ромбическая, свободная татура и др.

Основная характеристика сортов сливы домашней селекции СКФНЦСВВ представлена ниже: 
Глава 2. Интродукция и сортоизучение

'Прикубанская'. Сорт создан в СКЗНИИСиВ от скрещивания сортов 'Венгерка ажанская' и 'Ренклод зелёный' Сорт включен в Госреестр по Северо-Кавказскому региону. Дерево среднерослое, крона шаровидная, раскидистая. Сорт зимостойкий, засухоустойчивость средняя, устойчив к грибным болезням. Вступает в плодоношение на 4-5-й год после посадки. Плоды выше средней величины, 30-35 г, овальные, тёмно-синие, несколько неправильной формы. Мякоть зеленовато-жёлтая, сочная, вкус гармоничный (4,5 балла).

Биохимический состав плодов: сухих веществ - 14-15\%, сахаров - 10-12 \%, кислот - 0,7-0,9\%, витамина C $-5,2$ мг/100 г. Срок созревания - среднепоздний (конец августа). Урожайность высокая - 17,5-18,0 т/га.

'Краснодарская'. Сорт создан в СКЗНИИСиВ от скрещивания сортов 'Венгерка ажанская' и 'Великий Герцог'. Сорт находится в государственном сортоиспытании по Северо-Кавказскому региону. Дерево среднерослое, крона раскидистая. Зимостойкость средняя, засухоустойчивость высокая, относительно устойчив к грибным болезням. Скороплодный, вступает в плодоношение на 3-4 год. Плоды выше среднего размера, 40-45 г, хорошего вкуса, универсального назначения. Мякоть зеленовато-жёлтая, вкус гармоничный (4,7 балла).

Биохимический состав плодов: сухих веществ - 16,7 \%, сахаров $12,2 \%$, кислот - 1,8 \%, витамина $\mathrm{C}-4,4$ мг/100 г. Срок созревания средний (вторая декада августа). Урожайность высокая - 20,5 т/га.

'Милена'. Создан в СКЗНИИСиВ от скрещивания сортов 'Изюм кубанский' и 'Венгерка итальянская'. Сорт включен в Госреестр по Северо-Кавказскому региону. Дерево выше среднего роста, крона округло-овальная, приподнятая. Засухоустойчивость средняя, зимостойкость высокая, высокая устойчивость к основным грибным болезням. В плодоношение вступает на 5-6 год. Плоды крупные, 40-45 г, округлой формы, фиолетово-красные с белыми подкожными точками и слабым восковым налётом. Десертный сорт. Мякоть зеленовато-жёлтая, вкус гармоничный (4,8 балла). Биохимический состав плодов: сухих веществ - 20,2 \%, сахаров - 14,8 \%, кислот - 1,0 \%, витамина C - 3,9 мг/100 г. Срок созревания - среднепоздний (третья декада августа). Урожайность высокая - 18,0 т/га.

'Подруга'. Сорт создан в СКЗНИИСиВ от скрещивания сортов 'Венгерка ажанская' и 'Великий Герцог'. Сорт находится в государственном сортоиспытании по Северо-Кавказскому региону. Дерево среднерослое, крона шаровидная, раскидистая. Зимостойкость и засухоустойчивость высокие, устойчив к грибным болезням. Вступает в плодоношение на 5-6 год. 
Плоды крупные 40-45 г, округлые, красные, хорошего вкуса (4,8 балла). Мякоть жёлтая, сочная. Плоды транспортабельны. Биохимический состав плодов: сухих веществ $-28,4 \%$, сахаров $-20,7 \%$, кислот - 0,96 \%, витамина C - 11,8 мг/100 г. Срок созревания - поздний (первая декада сентября). Урожайность высокая - 19,5-20,2 т/га.

'Герцог'. Сорт создан в СКЗНИИСиВ от скрещивания сортов 'Метелка' и 'Великий Герцог'. Сорт находится в государственном сортоиспытании по Северо-Кавказскому региону. Дерево среднерослое, компактное. Зимостойкость средняя, засухоустойчивость высокая, относительно устойчив к грибным болезням. Вступает в плодоношение на 5-6 год.

Плоды крупные 45-50 г, удлинённо-овальные, фиолетово-синие с сильным восковым налётом, подкожные точки малозаметные, вкус гармоничный (4,7 балла). Биохимический состав плодов: сухих веществ - 16,8 \%, сахаров - 12,3\%, кислот - 1,3\%, витамина C - 3,3 мг/100 г. Срок созревания - средний (вторая декада августа). Урожайность средняя - 16,0-17,5 т/га.

'Красотка'. Сорт создан в СКЗНИИСиВ от скрещивания сортов 'Кабардинская ранняя' × 'Стенлей'. Сорт находится в государственном сортоиспытании по Северо-Кавказскому региону. Дерево среднерослое, компактное. Зимостойкость высокая. Засухоустойчивость хорошая. Устойчивость к основным болезням хорошая. Вступает в плодоношение на 5-6 год.

Плоды выше среднего размера 30-35 г, оранжевого цвета, овальные, с розовым румянцем и интенсивным восковым налётом, сочные. Приятного кисло-сладкого вкуса (4,7 балла). Биохимический состав плодов: сухих веществ - 21,8 \%, сахаров - 15,9\%, кислот - 0,75\%, витамина $\mathrm{C}-21,2$ мг/100 г. Срок созревания - поздний (первая декада сентября). Урожайность высокая - 17,0-18,4 т/га.

'Чародейка'. Сорт создан в СКЗНИИСиВ от скрещивания сортов 'Анна Шпет' × смесь. Сорт находится в государственном сортоиспытании по Северо-Кавказскому региону. Дерево среднерослое, крона раскидистая, ветви пониклые, редкая. Плоды очень крупные (55-70 г), средняя масса 62,5 г, овальные, пурпурно-фиолетовые, с сильным восковым налётом, подкожные точки малозаметны. Мякоть нежная, тающая, сладкая, жёлтого цвета (4,7 балла). Плоды одномерные, собраны в кисти по 4-7 плодов. Содержание сухих веществ - 16,0 \%, сахаров - 11,7 \%, кислот - 1,2 \%, аскорбиновой кислоты - 3,9\%. В плодоношение дерево вступает на 4-5 год после посадки Зимостойкость древесины - высокая, устойчивость цветковых почек к весенним заморозкам - выше средней. Засухоустойчивость средняя. Сорт устойчив к основным болезням и вредителям. Самобесплодный. Урожайность высокая - 19-21,5 т/га. 
Глава 2. Интродукция и сортоизучение

Плоды пригодны для употребления в свежем виде и для переработки (компоты, соки, джемы, варенье, сухофрукты).

В Государственный реестр селекционных достижений РФ по Северному Кавказу включены сорта сливы домашней селекции СКФНЦСВВ - 'Прикубанская’ и 'Милена'. В Государственном сортоизучении находятся сорта 'Подруга', 'Герцог', 'Красотка' и 'Чародейка'. Получено 3 патента на сорта 'Герцог', 'Подруга' и 'Милена' [3].

\title{
Библиографический список
}

1. Алехина Е.М., Заремук Р.Ш., Говорущенко С.А. Основы оптимизации сортимента косточковых культур на юге России // Вестник Российской академии сельскохозяйственных наук. - 2006. - № 4. - C. 55-58. - ISSN: 2500-2082.

2. Атлас лучших сортов плодовых и ягодных культур Краснодарского края. - Т. 2. Косточковые культуры. - Краснодар: СКЗНИИСиВ, 2009. - 232 с.

3. Государственный реестр селекционных достижений РФ, допущенных к использованию. Сорта растений. - М., 2017. - Т. 1. - С. 34-38.

4. Егоров Е.А., Ильина И.А., Заремук Р.Ш., Мирончук В.А. Разработка механизмов формирования предложений научно-технических программ агропромышленного комплекса на основе анализа инновационной восприимчивости производственных субъектов // Наука Кубани. - 2007. - № S. - C. 62-68. - ISSN: 1562-9856.

5. Заремук Р.Ш., Алехина Е.М., Доля Ю.А. Генетические ресурсы косточковых культур для создания новых сортов на юге России [Электронный ресурс] // Плодоводство и виноградарство Юга России. - 2011. - № 10(4). - C. 31-41. - URL: http:// journalkubansad.ru/pdf/11/04/03.pdf (дата обращения: 22.03.2018). - ISSN: 2219-5335. 6. Bozovic D., Jacimovic V. Pomological - technological properties of plum cultivars grown in northern Montenegro // Vocarstvo. - 2011. - Vol. 45. - № 175-176. - P. 117-122. 7. Nenadović-Mratinić Evica, Milatović Dragan, Durović Dejan. Biološke osobine sorti šljive kombinovanih svojstava // Voćarstvo. - 2007. - Vol. 41. - C. 31-35.

\section{CULTIVARS OF DOMESTIC PLUM FOR OPTIMIZING SOUTHERN ASSORTMENT}

\section{Zaremuk R. Sh.}

\author{
Federal State Budgetary Scientific Institution \\ "North-Caucasian Federal Research Centre for Horticulture, Viticulture, Wine-making", \\ c. Krasnodar, Russia, e-mail: zaremuk_rimma@mail.ru
}

The paper presents some cultivars of domestic plum belonging to domestic breeding; they were created in unstable and stressful environment and are characterized by high adaptive and productive potential. The cultivars of local breeding 'Prikubanskaya', 'Krasnodarskaya', 'Milena', 'Podruga', 'Gertsog', 'Krasotka' and 'Charodeika' differ from a number of introduced and standard cultivars by the main economic characteristics such as: drought and winter resistance, resistance to major diseases, productivity (early fertility, fruiting period, yield) and fruit quality (weight and size of fruit, biochemical composition, tasting evaluation). There is a full characteristics of the new cultivars of domestic plum belonging to domestic breeding; they were transferred to the State Cultivar Testing and included to the State Register 
Субтропическое и декоративное садоводство (66)

of Breeding Achievements for wide industrial use in the North Caucasus. The presented cultivars of domestic plum are recommended with the aim to optimize modern assortment and for further breeding work as sources of valuable traits.

Key words: plum, cultivar, breeding, adaptability, productivity, fruit quality.

УДК $635.918+635.912$

doi: $10.31360 / 2225-3068-2018-66-40-47$

\title{
УСТОЙЧИВОСТЬ В СРЕЗКЕ ПОБЕГОВ ВЕЧНОЗЕЛЁНЫХ ВИДОВ ОРАНЖЕРЕЙНЫХ РАСТЕНИЙ
}

\author{
Кабушева И. Н., Сак Н. Л., Катковская Н. С., Сандрозд Ю. И. \\ Государственное научное учреждение \\ «Центральный ботанический сад Национальной академии наук Беларуси», \\ 2. Минск, Республика Беларусь, e-mail: kabusheva_hbc@mail.ru
}

В статье излагаются результаты изучения длительности сохранения срезанных побегов у 21 вида вечнозелёных тропических и субтропических древесных оранжерейных растений, принадлежащих к 17 семействам. Приведено описание морфологических признаков побегов и листьев, важных для характеристики их декоративных качеств как срезочной зелени. Исследованиями показано, что изученные виды характеризуются средней и высокой устойчивостью побегов в срезке (5-28 дней и более) и перспективны для расширения ассортимента стаффажной зелени как на отечественном, так и зарубежном флористическом рынке.

Ключевые слова: устойчивость в срезке, стаффажная зелень, вечнозелёные растения, оранжерейные растения, морфологические признаки побегов.

Анализ флористического рынка Беларуси за 2007-2011 гг., проведённый Е. А. Игнатович [1], показал, что цветочная продукция представлена следующими группами: рассада (однолетники, двулетники, многолетники), горшечные растения, а также срезка цветов (роза, тюльпан, гербера, фрезия, хризантема, гвоздика и др.) и зелени, используемой для украшения цветочных композиций (гипсофила, рускус и др.). На рассаду в структуре отечественного цветочного рынка приходится $24,35 \%$, незначительную часть занимает горшечная продукция - всего $1,7 \%$, и основную долю от реализации цветочной продукции составляет срез цветов и зелени - 73,95 \%, причём её удельный вес имеет неуклонную тенденцию к увеличению из года в год.

Мировой ассортимент срезочной зелени довольно обширен: около 150 наименований [7]. Основными импортёрами стаффажной зелени, цветов и флористических материалов на белорусский рынок являются Голландия, Польша, Россия, Турция, Танзания, Кения, Колумбия, Эквадор, Китай, Германия [4]. 